\title{
Cultural Competence Perspectives From Nurses in Four Asian Countries: A Qualitative Descriptive Study
}

\author{
Praneed Songwathana, R.N., Ph.D. ${ }^{1}$, Sopen Chunuan, R.N., Ph.D. ${ }^{1}$, \\ Karnsunaphat Balthip, R.N., Ph.D. ${ }^{1}$, Shutiwan Purinthrapibal, R.N., Ph.D. ${ }^{1}$, \\ Tao Hui, R.N., Ph.D. ${ }^{2}$, Kusman Ibrahim, R.N., Ph.D. ${ }^{3}$, Luu Thi Thuy, R.N., Ph.D. ${ }^{4}$ \\ ${ }^{1}$ Faculty of Nursing, Prince of Songkla University, Hat Yai, Songkhla 90112, Thailand. \\ ${ }^{2}$ Kunming Medical College, Kunming, China, \\ ${ }^{3}$ Faculty of Nursing, Padjadjaran University, Bandung, Indonesia. \\ ${ }^{4}$ Da Nang University of Medical Technology and Pharmacy, Da Nang, Vietnam. \\ Received 12 June 2020 • Revised 10 July 2020 • Accepted 20 July 2020 • Published online 27 October 2020
}

\section{Abstract:}

Objective: This study aimed to describe the perception of cultural competence (CC) among nurses of four Asian countries.

Material and Methods: A descriptive qualitative study was carried out, including fourteen nurses for in-depth interviews and 63 nurses for 8 focus group discussions being purposively selected from four Asian countries. Data were analyzed based on content analysis.

Results: The participants defined CC as similar to cultural care, and described their CC in four main themes: (1) caring focus for patients with different cultures, (2) valuing holistic care/ patient-centered nursing, (3) preparing for living with God or Buddha, and (4) considering the social norms and patient rights. Assessment of the patient's cultural background and myths contrary to medicine, along with having professional nursing knowledge, skills, and experience were the components of CC.

Conclusion: The participants have addressed their CC in providing culturally, congruent care with a universal, holistic, and empathetic approach. Nurses should be trained to develop skills in multicultural care and language and made aware of their patients' cultural beliefs. Further, CC scales for nurses working in the selected, four Asian countries should be developed.

Keywords: Asian nurses, cultural competence, perceptions

Contact: Assoc. Prof. Praneed Songwathana, R.N., Ph.D.

Faculty of Nursing, Prince of Songkla University, Hat Yai, Songkhla 90112, Thailand.

E-mail: praneed.s@psu.ac.th

(c) 2020 JHSMR. Hosting by Prince of Songkla University. All rights reserved.

This is an open access article under the CC BY-NC-ND license

(http://www.jhsmr.org/index.php/jhsmr/about/editorialPolicies\#openAccessPolicy).
J Health Sci Med Res 2021;39(1):57-66 doi: 10.31584/jhsmr.2020767 www.jhsmr.org 


\section{Introduction}

Cultural diversity such as differences in traditions, behaviors, moral and ethical values, perception towards health and illness and language competence might affect the health and wellbeing of an individual. ${ }^{1}$ Globalization, increasing trends of migration, technological advancement ${ }^{2,3}$, fertility rates, diverse races, ethnicity and changing population characteristics ${ }^{3}$ contribute to creating a culturally diverse group of inhabitants around the world ${ }^{2}$, and demand an evolution in culture. ${ }^{3}$ Additionally, multicultural populations in health sectors are increasing, because of student exchange programs between universities and the migration of nurses for employment. ${ }^{2}$ However, some health care professionals are not fully prepared to provide care to patients in consideration of cultural diversity. ${ }^{4}$ As a result, they are facing many challenges to meet the demands of patients, families, and societies as a whole. ${ }^{3}$ Although, culturally congruent care is the fundamental right for every human being, mismatches of health care demand between patients and health care providers in everyday nursing practice and health care settings could impact health care outcomes, psychological states and satisfaction of patients. It is essential for today's world to increase cultural growth, specific nursing interventions and caring based on population needs. ${ }^{3}$

Globally, Asia is the major mainland source of international migrants. China, the Russian Federation and Bangladesh are the main exporters around the world. ${ }^{5}$ In the Asian context, around 275 million people, aged ranged between 15 and 64, will be mobilized within East Asia (For example Singapore, Malaysia, Vietnam, and particularly Thailand) by 2030. The exporting countries will be China, Myanmar, Indonesia, and the Philippines. ${ }^{6}$ This scenario might increase the inhabitants of said countries with diverse races, cultures and religious beliefs. ${ }^{7}$ The literature has emphasized that patient care might be inappropriate and face cultural conflict, because of a lack of understanding of diverse cultures, beliefs, language competence and differences in living habits. ${ }^{8}$ Therefore, nurses should prepare themselves for readiness in providing culturally competent care.

Conceptually, cultural competence (CC) is the means through which nurses can acquire understanding and respect the differences among patients of different cultures. ${ }^{9}$ In addition, Campinha-Bacote ${ }^{10}$ highlighted that CC is a continuous process, focusing on a person's capability to work effectively with patients or clients of a diverse cultural and ethnic background; with cultural awareness, knowledge, skills, cultural encounters and desire. Therefore, CC nurses should be able to work with diverse patients at any time or place, understand their unique preferences and plan for individualized care to meet their expectations. $^{2}$ This could also improve the quality of nursing care and the patient outcome $e^{9,11}$, and facilitate communication and accommodation of patient's preferences. ${ }^{4}$ To promote and prepare for the CC of nurses, it is essential to understand what nurses from different contexts perceive CC.

A previous integrative review reported that the majority of instruments assessed the self-perception of nurses regarding their $\mathrm{CC}$ to care for a patient from the general population, with the possibility of a socially desirable answer. $^{12}$ Therefore, there is a need to develop empirically supported instruments to measure $\mathrm{CC}^{13}$; especially focused on the nursing workforce in Asian countries, where such studies have been less conducted. Current knowledge, regarding nurses' CC questions the relevance of the available measures of nurses in Asia, to fit the context of a multicultural society was sought. This study is the first phase in understanding the CC development model, which aimed to describe the perception of $\mathrm{CC}$ of Asian nurses from Thailand, China, Vietnam, and Indonesia. The four countries were selected as the representatives of unique Asian cultures where there is an increasing 
migration trend in intra-ASEAN (Association of Southeast Asian nations) labor ${ }^{14}$ wherein Thai nurses are being mainly exposed to these of Asian countries. The findings should be helpful to identify multicultural training needs, develop the instruments, and enable researchers, educators and administrators to assess and evaluate a nurse's CC.

\section{Material and Methods}

A descriptive qualitative study was conducted at general, public hospitals located in the city of four selected countries in Asia (Thailand, Indonesia, China and Vietnam). The study settings were purposively selected from the doctoral nursing network, initiated by the Faculty of Nursing, Prince of Songkla University (PSU).

Participants were registered nurses $(R N)$ and nurse leaders (NL), who had been working for at least one year in selected general, public hospitals. All nurses $(n=77)$ having experiences in delivering cross-cultural care, able to communicate in their local language, and willing to participate in the study were recruited from the nursing departments of each hospital. From this, available participants were purposively selected for in-depth interviews (IDIS) $(n=14)$ and 8 focus group discussions (FGDs) ( $n=63$ ). Participants from the selected countries consisted of: Thailand $(n=20)$, Indonesia $(n=18)$, China $(n=19)$, and Vietnam $(n=20)$ nurses.

Ethical approval from the Center for Social and Behavioral Sciences Institutional Review Board, PSU (PSUIRB 2018-NL008), and permission from each country setting were obtained before data collection. Ethical principles were followed by obtaining written informed consent, and maintaining confidentiality and privacy. They were also informed about the right to withdraw from the study at any time, without penalty. None of the participants refused or dropped out of the study.

Data were collected during November, 2018 to May, 2019; after all researchers were trained to be qualitative researchers in a doctoral thesis class, workshop, and onsite consultation. Similar procedures for data collection were applied in each group. The researchers were welltrained to be an instrument, using a semi-structured question guideline for face-to-face IDI and FGDs. This instrument was pilot tested among PSU nurses, before the commencement of the actual study, and was modified based on the participants' responses. Examples of questions are: "What is your understanding about culture and cultural care, and how do you define it? What are the components of CC?" Any following, probing questions were based on the participants' response. A tape recorder and field notes were used as accessory materials. Forward and backward translation of the interview, and the FGDs guidelines were performed using bilingual translators of each country, before proceeding to data collection.

Because of a limited budget, consideration was given by including at least 1 participant in each group from each country for an IDI and FGDs (Table 1). FGDs, with two homogeneous groups of RN and NL of each country, were assembled with a group size ranging from 7 to $10 .^{15}$ Selected participants in each group participated in the IDIs, so as to encourage their viewpoints on $\mathrm{CC}$, until data saturation was achieved. The duration of the IDIs and FGDs was approximately 45 to 60 minutes, as per the recommendation of Wong $^{15}$ and Brouneus ${ }^{16}$, respectively. All interviews and FGDS were conducted at their offices, with a few followed up by a second interview via phone, to clarify and validate some points.

The translation validation process ${ }^{17}$ of the transcripts of interview and FGDs were adopted using bilingual translators from each country. Data in its original language were analyzed using a manual content analysis approach. ${ }^{18}$ Content analysis was chosen, because it was suitable to analyze the importance and meaning of nursing phenomena, and simple reporting of the common issues 
mentioned in the data. The principal investigator (PI) and all co-investigators $(\mathrm{Cls})$ created the coding, identified categories in English and validated it with the original data. The $\mathrm{Pl}$ and one $\mathrm{Cl}$ from each country verified the categories, identified the main themes and chose the excerpts supporting the themes to present the context. The core components of CC were extracted and constructed to the themes. Similarities and differences in perspectives of CC across the country, or groups were extracted into a table and presented.

Table 1 Nursing participants from four countries

\begin{tabular}{lllllll}
\hline \multirow{2}{*}{$\begin{array}{l}\text { Group } \\
\text { Data }\end{array}$} & \multicolumn{2}{l}{ Professional nurses } & & \multicolumn{2}{l}{ Nurse leaders } & Total \\
collection & FGD & IDI & & FGD & IDI & \\
\hline Thailand & 8 & 2 & & & & \\
Indonesia & 7 & 1 & & 9 & 1 & 18 \\
China & 8 & 2 & & 7 & 2 & 19 \\
Vietnam & 8 & 2 & & 8 & 2 & 20 \\
\hline Total & 31 & 7 & 32 & 7 & 77 \\
\hline
\end{tabular}

$F G D=$ focus group discussion, IDI=in-depth interview

The principles of trustworthiness were used to ensure the study rigor, based on Lincoln, Guba. ${ }^{18}$ Credibility was enhanced by member checking and methodology triangulation. Confirmability was accomplished through the inquiry audit of the process, and by using a voice recorder, transcribing word by word and analyzing the data simultaneously. The research findings were confirmed, to verify accurate information, through $\mathrm{Cls}$ being made aware of subjectivity, by using member checking and peer review.

\section{Results}

The participant's characteristics. Almost all of the 77 participants were female, and aged between 25 and 52 years of age. Thirty-five of them had no religion, while among the others 23, 16 and 3 participants were Buddhist, Muslim, and Christian, respectively. In concerns to training and communication ability, only 15 participants had received training on multicultural care, and only 47 participants could communicate in an international language. However, their clients whom they cared for were mostly from different cultures (Table 2).

CC: general view. Due to unclear terms when first being asked about CC all participants initially explained their understanding of culture, this was then linked this to cultural care and their competence. Qualitative content analysis, regarding the CC perceived by Asian nurses, showed two main aspects, namely: (1) care for people in a different culture, and (2) components of CC. These are described as follows.

Care for people in a different culture. Participants from the four countries described that cultural care was the care for the patient of a different culture (differing from their own), providing holistic patient-centered care following social norms in both familiar and unfamiliar situations and enabling communicate in a different language. The care for people in different cultures comprised of four subthemes.

Caring focus for patients with different cultures.

All participants mentioned that cultural care was caring for patients with diverse cultures, having different backgrounds, beliefs, customs, lifestyles, religions, and different languages from different regions. Examples from Vietnamese and Thai participants were described as:

"Cultural care is caring for patients coming from many different regions, with different backgrounds, customs, religions, and cultures like Thai, Vietnamese and Chinese." (Vietnamese-RN-FGD)

"Cultural care is the caring for patients, who have different cultures; such as, beliefs, backgrounds, customs, ways of living and religions. It also includes caring with empathy for a person who has a different I anguage and clothing, which makes them have significance as a whole person." (Thai-NL-FGD) 
Table 2 Demographic characteristics of nursing participants from four countries

\begin{tabular}{|c|c|c|c|}
\hline Demographic characteristics & $\begin{array}{l}R N \\
n=38\end{array}$ & $\begin{array}{l}N L \\
n=39\end{array}$ & $\begin{array}{l}\text { Total } \\
\mathrm{n}=77\end{array}$ \\
\hline \multicolumn{4}{|l|}{ Gender } \\
\hline Female & 37 & 33 & 70 \\
\hline Male & 1 & 6 & 7 \\
\hline \multicolumn{4}{|l|}{ Age (years) } \\
\hline 20-30 & 8 & - & 8 \\
\hline $31-40$ & 12 & 9 & 21 \\
\hline $41-50$ & 8 & 21 & 29 \\
\hline$>50$ & 8 & 9 & 17 \\
\hline \multicolumn{4}{|l|}{ Religion } \\
\hline Buddhist & 10 & 13 & 23 \\
\hline Muslim & 7 & 9 & 16 \\
\hline Christian & 3 & - & 3 \\
\hline None & 18 & 17 & 35 \\
\hline \multicolumn{4}{|l|}{ Period of working in years } \\
\hline $1-3$ & 2 & - & 2 \\
\hline $4-6$ & 2 & 1 & 3 \\
\hline $7-10$ & 8 & 5 & 13 \\
\hline$>10$ & 16 & 23 & 49 \\
\hline \multicolumn{4}{|c|}{ Traveling/visiting experiences in other countries (beyond their own country) } \\
\hline Asian country & 3 & 5 & 8 \\
\hline Western/other than Asia & 2 & 5 & 7 \\
\hline None & 33 & 29 & 62 \\
\hline \multicolumn{4}{|l|}{ Training experience in multicultural care } \\
\hline Yes & 9 & 6 & 15 \\
\hline No & 29 & 33 & 62 \\
\hline \multicolumn{4}{|l|}{ Language ability/iteracy in communication* } \\
\hline Local language & 27 & 28 & 55 \\
\hline National language & 28 & 31 & 59 \\
\hline International language & 22 & 25 & 47 \\
\hline \multicolumn{4}{|l|}{ Experiences in caring for clients (mainly) } \\
\hline Similar to your culture & 6 & 23 & 29 \\
\hline Different from your culture (another culture) & 32 & 16 & 48 \\
\hline
\end{tabular}

*more than one answer

$\mathrm{RN}=$ registered nurses, NL=nurse leaders

Valuing holistic care or patient-centered nursing. Almost all of the participants explained that cross-cultural care was holistic care, considering the holistic view on bio-psychosocial and spiritual aspects of patient-centered care. They elaborated the essence of nursing care as identifying specific, cultural backgrounds, focusing on the patients actual needs, providing spiritual care for promoting quality of life, understanding the family's way of life, belief and faith, and adjusting to patient cultures. Additionally, attention to individualize care, awareness, and familiarity on cultural care were most important, as the following participants stated.

"If we know the specific culture, we can provide holistic care... If we know he or she was unable to eat pork, we would not force them to eat it, and we can share our living." (Thai-RN-FGD) 
"Cultural care is the patient-centered approach, and the beliefs of being a patient-centered approach, with different individuals having cultural differences." (Chinese$\mathrm{NL}-\mid \mathrm{DI})$.

"The understanding and caring are based on the holistic perspectives of the patients and holistic care or patient-centered care in nursing." (Indonesian-RN-IDI)

Preparing for living with God (Allah) or Buddha. Thai participants particularly explained that CC was the response to the patient's life goal, and the preparation for living with God, or other spirituality, based on their religious beliefs, and delivering humanized care for a peaceful death.

"Muslims are easier to care for when they are in sickness. He or she is ready to go to be with God (Allah) and accept the last stage of life. So, we feel easy to provide palliative care, the aim of care is not for survival, but for living with god." (Thai-NL-FGD)

"Thai or Myanmar patients who are a strong Buddhist, I cared for him when he was in the dying process. In the last stage of him, we brought the Buddha to him, which was his faith, he then passed away peacefully. This may be like humanized care too." (Thai-NL-IDI).

Considering the social norms and patient rights. Some participants, mostly Thai, expressed that crosscultural care facilitated the provision of traditional care and accommodated the patient to their cultural practice, by considering their social norms and the patients' rights as the following statements.

"From familiarity, we then feel competence and have no problem with care provision. Cross-cultural care is attentive to traditional care and social norms. For example, palliative care in Chinese patients, they would adhere to gratitude by allowing the patient to be with them as long as possible" (Thai-NL-IDI)

"For western patients, they usually inform and ask/request for their right to know information and service... the patient has a request for reasons to have a heparin lock he said that he had a right to choose or allow nurses to do." (Thai-NL-FGD)

"From experience in Tsunami, clients (foreigner) always asked for their rights such as when pain occurred, they asked for Pethidine and told me to do things as they need... They liked asking but we do not get used to it (as their culture) opposite to Thai people who rarely asked." (Thai-RN-FGD)

Components of CC. Although, the concept of CC is abstract, broad and confusing some participants explained that CC was something they often work with, but did not perceive it before. Almost all participants mentioned that the nurse's communication skills with patients from a different culture, or for those having a different, native language than their own, were essential component of CC care. CC was the nurses' general caring competence, and was greatly influenced by the nurse's culture. Additionally, all Thai participants agreed that the nurse's had adequacy of knowledge on the disease, illness, and treatment supporting the choice of appropriate methods, or the adaptation of methods, to respond to the needs within the patient's cultural context. It was essential for nursing professions to understand a culture, provide holistic care, develop trust and make a care plan, focusing on the patient's information and needs; including the bridge between the relationship of nurses and their patients. A similar view about the components of CC was described as: (a) assessment of the patient's cultural background, and myths contrary to medicine, and (b) having professional nursing knowledge, skills and experiences.

Assessment of the patient's cultural background and myths, contrary to medicine. The majority of participants mentioned that assessment of the patient's cultural back ground was a vital component of CC, which helped them to understand the culture of the patients. Thai participants in particular expressed their experience that understanding the culture of a patient along with myths related to medical care for achieving holistic care as well as individualized 
care was one of the important components of CC. They stated that experiences helped them learn about the patients' mind and spirit, and guide them in the caring of patients with empathy. The more they learned about the culture, the better they could provide a better quality of nursing care, and gain the trust of their patients. It not only helped them gain a better understanding of people or clients holistically, not only for physical care, but also in creating trust and strengthening the relationship, by acknowledging the cultural needs for making an appropriate plan; as per the following statements.

"It is the trust of the patient; it helps the patient to tell the true story. If we don't know their background well, it would make them feel un-trust. If we know their culture, it would help us understand and take concern more not only in physical care. For example, if we know he or she was unable to eat pork, we would not force to eat and we can share our living." (Thai-RN-FGD)

"Assessment of the patient's cultural background, including power, money, personality, work status, family relationship, family attitude towards the patient, patient's understanding of the care and life status. It is the component of cultural competence. Assessment for the provision of individualized care, such as patients with stoma adaptation or maladaptation is the component of cultural competence." (Chinese-NL-IDI)

"We are in maternity. So, we often face the problem which the society's culture contradicting with many myths. We as the health workers need to learn the culture in the society to eliminate those myths that are contrary to the medical." (Indonesian-RN-IDI)

Having professional nursing knowledge, skills and experiences. Thai and Chinese participants added the components of CC in terms of having soft skills, such as the ability to communicate in the same language, having risk assessment, critical thinking, experiences, analyzing, managing and coordinating ability, observation skills and skills for gaining trust. These skills are essential for human caring, helped to understand ways of life, and beliefs of both patients and their families. In addition, learning from experiences was helpful in increasing the nurse's ability to communicate with patients and relatives.

"The component of cultural competence is having professional nursing knowledge and skills both in general knowledge and skills and nursing specialty, as well as the cooperative ability, which is favorable to gain the trust of patients." (Chinese-RN-FGD)

"Nurses should observe and be sensitive to the client's feeling of non-satisfaction, they should concern about unusual or different voice. So, nurses need experiences and a specific personality for coordination in case of complex and seek assistance from the head nurse or me, or an executive person or administration level to manage. Therefore, to deal with the complex problem, it requires both experiences and personality like a person called "Mae Pranom team (a person who can negotiate)" (Thai$\mathrm{RN}-\mathrm{FGD})$

"Nurse must have critical thinking, ability to analyze the case, disease and think holistically including the aim of care and treatment. Nurses need to understand the way of life, the belief of patients and families which might affect the decision making such as Muslim believe in god and accept death or dying easily, and take the patient back home... Trust' is often created by a similar culture. Nurses who are Muslim, would more likely to easily communicate or contact, not because of language. For example, we send experienced nurses to deal with the nursing problem and find a good approach to make them trust and follow, we sometimes contact a religious leader." (Thai-NL-IDI)

\section{Discussion}

Seventy-seven participants, from four Asian countries, described their perception of CC; based on their cultural backgrounds, such as their religious groups; for instance, Buddhists, Muslims, and Christian along with a no religion 
group. The majority of nurses did not have experience of traveling to another country, or training in multicultural care. Although, 47 participants had the ability to communicate in an international language, all had experience in caring for culturally diverse patients for at least one year. Additionally, although most participants did not have experience of travelling to another country or training in multi-cultural care, their working experiences at hospitals was for more than 6 years, and in that time they had provided care to clients differing from their own culture (Table 2). They could also ensure their learning and exposure of clients from various cultures, which is similar to a previous study in Thailand. ${ }^{19}$

Regarding participant's perception of CC, care for people with different cultures was commonly described as ways in which individuals understood, behaved, and interacted with each other within a holistic approach. This is a similar to the view of cultural care, which reflects that people have complex and dynamic understandings of their health, and need individualized, patient-centered and holistic care within a cultural context. ${ }^{3}$ Therefore, the view of culture, and the power it plays in the construction of culture, is important for nurses to understand. In this study, the participants' view of caring for patients, with different cultures, also focused on beliefs, customs, lifestyles, religions, and different languages from different regions. This is congruent with a previous study ${ }^{20}$ that highlighted the importance of cultural awareness, and culturally sensitive care; considering client's cultural beliefs, lifestyles, customs, values, tradition, preferences, concern, gender and ethnicity.

Moreover, the participants reported that cultural was similar to holistic care, which gave attention to the bio-psychosocial and spiritual aspects of patients. Again, this is congruent with the concept of holistic health and $\mathrm{CC}^{21}$ Likewise, the provision of holistic care to patients, by valuing a patient's culture, ethnicity, language, religion, country of residence, family, age and gender, were essential; which is similar to the perception by nurse practitioners. ${ }^{22}$
Thai participants in particular perceived cultural care as patient-centered nursing, with this being the preparation of patients for living with God (Allah) or Buddha, and the care provision by considering the social norms and patient rights. This was regarded as unique findings, compared to those of other Asian countries. Literature emphasized that nurses often encountered a problem, and create a conflict, and patient care might be delayed because of the diverse culture, beliefs, language competence, and differences in living habits. ${ }^{8}$ However, the participants tend to be flexible and understand the context which facilitated their provision of timely and need-based holistic care to patients, by avoiding conflict. This is similar to a previous study in southern Thailand where it was recognized as areas of multicultural settings. ${ }^{19}$

The findings were consistent with previous literature, in that $\mathrm{CC}$ is the people's ability to understand and communicate well ${ }^{23,24}$, work effectively, build a meaningful relationship with different people from different cultural and ethnic backgrounds (for example, beliefs, customs, and behaviors) ${ }^{24}$ apply ethical principles ${ }^{25}$ with trust, and demonstrate respect to patients from diverse cultures. ${ }^{23}$ Furthermore, CC is a vital component for promoting selfawareness, social skills and behaviors in cultural diversity and developing the ability for advocacy to others. ${ }^{24}$ Understanding of cultural care of the participants, in this current study, is congruent with the meaning of CC as revealed in prior literature. ${ }^{10}$ Due to less experience of traveling oversea and training in multicultural care, no different views of $\mathrm{CC}$ from nursing participants from the four countries were found in this study.

Concerning the components of $\mathrm{CC}$, assessing and understanding the patient's cultural background was important. Although, there might be differences in patient backgrounds, beliefs and preferences; even in the same culture, acknowledgment of these differences is the most important aspect. ${ }^{21}$ A mixed-methods study in the United States of America showed similar findings, regarding the 
assessment and development of rapport with patients promoted an understanding of the cultural backgrounds, and helped to gain trust from the patients. ${ }^{19}$ Likewise, the assessment of patient's myths related to medical care was also necessary to provide CC nursing services. This finding is congruent with a previous study in that understanding patient myths and taboos is essential to facilitate quality health services. ${ }^{21}$

Thai and Chinese participants also reflected CC through their experience to facilitate the efficient and effective assessment of culture, for providing culturally congruent care. This finding is similar to previous studies among nurses in Thailand ${ }^{22}$ and Taiwan ${ }^{26}$, in that prior experience created a positive outlook on the cultural needs of the people. Since health assessment is the main focus in nursing skills, assessment of culture is important to be integrated in daily practice, because it acts as the basis for being culturally competent and providing culturally specific nursing care. ${ }^{27}$ Therefore, this finding showed professional nursing knowledge and skills are essential for CC, which is consistent with Campinha-Bacote10 who mentioned that cultural awareness, knowledge, skills, attitude, engagement and wishing to engage are the building blocks of CC.

\section{Conclusion}

Asian nurses perceived their CC care in a holistic and patient-centered approach. Nurses have recognized the need to understand and value individual beliefs in preparing patients to live with God or Buddha, and to provide care considering social norms and patient rights. The essential components of $\mathrm{CC}$ are in assessing the patients' cultural background and utilizing professional nursing knowledge, skills and experience. This qualitative study was only conducted in four, selected Asian countries and had a time limitation due to a small grant. Hence, the findings limit generalizable in covering $\mathrm{CC}$ from all Asian culture and nurses. However, the similarities of CC perspectives should be well-acknowledged, to develop a useful scale by adding some beliefs and values of religion, social norms and patient's right; including, the needs based on holistic care in the existing CC assessment tools, and to evaluate psychometric properties in the future.

\section{Acknowledgement}

This study was supported by the Faculty of Nursing, Prince of Songkla University. The authors acknowledge the willingness of participants to share their experiences and appreciate Dr. Alan Guiter for the editing of this paper.

\section{Funding sources}

This work was supported by the Faculty of Nursing, Prince of Songkla University (grant 625.1016).

\section{Conflict of interest}

There are no conflicts of interest in this study.

\section{References}

1. Almutairi AF, Adlan AA, Nasim M. Perceptions of the critical cultural competence of registered nurses in Canada. BMC Nursing 2017;16:1-9.

2. Bjarnason D, Mick J, Thompson JA, Cloyd E. Perspectives on transcultural care. Nurs Clin N Am 2009;44:495-503.

3. Jeffreys MR. Teaching cultural competence nursing and health care: inquiry, action, and innovation. $3^{\text {rd }}$ ed. New York: Springer Publishing; 2016.

4. Busher Betancourt DA. Madeleine Leininger and the transcultural theory of nursing. The Downtown Review 2016;2:1-7.

5. Edes B. Migration in Asia: where is everybody going? [monograph on the Internet]. Metro Manina: Asian Development Blog; 2019 [cited 2020 Mar 2]. Available from: https://www.weforum. org/agenda/2019/02/migration-in-asia-where-is-every body-going

6. The Economist. Daily chart- migration and labour shortages in Asian countries [monograph on the Internet]. London: The Economist Newspaper Limited; 2017 [cited 2020 Mar 2]. Available from: https://www.economist.com/graphic-detail/ 
2017/02/10/migration-and-labour-shortages-in-asiancountries

7. Invest in ASEAN. Diverse ASEAN [monograph on the Internet]. Jakarta: The Association of Southeast Asian Nations; 2017 [cited 2020 Mar 2]. Available from: http://investasean. asean.org/index.php/page/view/about-the-asean-region/ view/707/newsid/930/diverse-asean.html

8. Wesolowska K, Hietapakka L, Elovainio M, Aalto AM, Kaihlanen AM, Heponiemi T. The association between crosscultural competence and well-being among registered native and foreign-born nurses in Finland. PLoS ONE 2018;13. doi: 10.1371/journal.pone.0208761.

9. Maier-Lorentz MM. Transcultural nursing: its importance in nursing practice. J Cult Divers 2008;15:37-43.

10. Campinha-Bacote J. The process of cultural competence in the delivery of healthcare services: a model of care. J Transcult Nurs 2002;13:181-4.

11. Suhonen R, Saarikoski M, Leino-Kilpi H. Cross-cultural nursing research. Int J Nurs 2009;46:593-602.

12. Loftin C, Hartin V, Branson M, Reyes H. Measures of cultural competence in nurses: an integrative review. Sci World J 2013;2013:1-10.

13. Substance Abuse and Mental Health Services Administration, U.S. A treatment improvement protocol: improving cultural competence [monograph on the Internet]. Rockville, Maryland: U.S. Department of Health and Human Services; 2014 [cited 2020 Mar 2]. Available from: https://store.samhsa.gov/sites/ default/files/d7/priv/sma14-4849.pdf

14. Pasadilla GO. Social security and labor migration in ASEAN [homepage on the Internet] Tokyo: Asian Development Bank Institute; 2011 [cited 2020 Mar 2]. Available from: https://www. adb.org/sites/default/files/publication/157275/adbi-rpb34. pdf

15. Wong LP. Focus group discussion: a tool for health and medical research. Singapore Med J 2008;49:256-61.

16. Brouneus K. In-depth interviewing: the process, skill and ethics of interviews in peace research. In: Hoglund $K$, Oberg M. editors. Understanding peace research: methods and challenges. London: Routledge; 2010;p.130-45.

17. van Nes F, Abma T, Jonsson H, Deeg D. Language differences in qualitative research: is meaning lost in translation? Eur J Ageing 2010;7:313-6.

18. Lincoln Y, Guba E. Establishing trustworthiness. In: Bryman A, Burgess RG, editors. Qualitative research (volumes III). London: Sage Publications; 1999;p.397-444.

19. Songwathana $P$, Siriphan S. Thai nurses' cultural competency in caring for clients living in a multicultural setting. Pacific Rim Int J Nurs Res 2015;19:19-31.

20. Shepherd SM, Willis-Esqueda C, Newton D, Sivasubramaniam $D$, Paradies $Y$. The challenge of cultural competence in the workplace: perspectives of healthcare providers. BMC Health Serv Res 2019;19:135-46.

21. Leininger MM, McFarland MR. Culture care diversity and universality: a worldwide theory for nursing. $2^{\text {nd }}$ ed. Sunbury, MA: Jones \& Bartlett Publishers; 2006.

22. Huerta CG, Kranz P, Maville JA. Perception of cultural competence in nurse practitioners. J Nurs and Health Sci 2015;9:1-16.

23. Centre for Research \& Education on Violence Against Women \& Children. What does it mean to be culturally competent? [homepage on the Internet]. Ontario: Centre for Research \& Education on Violence Against Women \& Children [cited 2020 Mar 4]. Available from: http://makeitourbusiness. ca/blog/what-does-it-mean-be-culturally-competent

24. de Guzman RMT, Durden TR, Taylor SA, Guzman JM, Potthoff KL. Cultural competence: an important skill set for the $21^{\text {st }}$ century [monograph on the Internet]. Agricultural Hall, Lincoln, United States: Nebraska Extension; 2016 [cited 2020 Mar 5]. Available from: http://extensionpublications.unl.edu/assets/ html/g1375/build/g1375.htm

25. Sherwood J. What is cultural competence? [monograph on the Internet]. Camperdown NSW: National Center for Cultural Competence, The University of Sydney; n.d. [cited 2020 Mar 5]. Available from: https://sydney.edu.au/nccc/aboutus/what-is-cultural-competence.html

26. Lin MH, Wu CY, Hsu HC. Exploring the experiences of cultural competence among clinical nurses in Taiwan. Appl Nurs Res 2019;45:6-11.

27. Andrews MM, Boyle JS. Transcultural concepts in nursing care. $5^{\text {th }}$ ed. Philadelphia: Wolters Kluwer/ippincott Williams \& Wilkins; 2008. 